\title{
Estudo Fotográfico da Arte Urbana: da Aventura Proibida ao Engajamento Político
}

\author{
Anita Rink \\ Universidade Salgado de Oliveira, RJ, Brasil. \\ Ione Vasques-Menezes \\ Universidade de Brasília, DF, Brasil. \\ Marsyl Bulkool Mettrau \\ Universidade do Minho, Portugal.
}

\begin{abstract}
Resumo: Expressões semióticas constituem-se por imagens carregadas de valores e conceitos que estão amplamente presentes no meio urbano e tornaram-se um fenômeno cultural da atualidade. A arte de rua é uma das formas de semiótica que tende a modificar o cotidiano social da cidade, embelezando, denunciando ou mesmo sendo incompreensível ao transeunte em geral. Este estudo, partindo de uma perspectiva histórico-social, tem o objetivo de indicar como as interferências da arte urbana produzem cultura e influenciam a construção do processo societário. Os dados foram coletados por meio de 100 fotografias feitas em municípios do Rio de Janeiro entre os meses de março de 2013 e abril de 2015 e entrevistas com 17 artistas de rua, tratadas pela análise de sentido. Os resultados sugerem que, embora exista uma codificação semiótica dominante nos espaços urbanos, a atuação dos artistas de rua expõe inúmeras outras vozes sociais que apresentam novas linguagens artísticas e atuações no espaço público que funcionam como micropolítica. Conclui-se que a arte de rua influencia a sociedade e ajuda a desnaturalizar a semiótica capitalista, democratizando as cidades e favorecendo que se entendam os locais públicos como sendo de uso comum.
\end{abstract}

Palavras-chave: Arte de Rua, Criatividade, Singularidade, Ambientes Urbanos.

\section{Photographic Study of Urban Art: from Forbidden Adventure to Political Engagement}

\begin{abstract}
Semiotic expressions are constituted by images which carry values and concepts that are widely present in urban areas and have become a cultural phenomenon these days. Street art is one of the forms of semiotics that tends to modify the social daily life of the cities, beautifying, denouncing, or even being incomprehensible to the passerby. This study, using a historical-social perspective, aims to indicate how the interferences of urban art produce culture in general and influence the construction of society itself. Data was collected through 100 photographs taken in cities around Rio de Janeiro State between March 2013 and April 2015 and interviews with 17 street artists studied by the analysis of meaning method. The results suggest that although there is a dominant semiotic form of codification of the urban spaces, the performance of street artists exposes countless other social voices that introduce new artistic languages and performances in the public spaces and act as micropolitics. We conclude that street art influences society and helps to denaturalize capitalist semiotics by democratizing cities and favoring the understanding of public places as places of common use.
\end{abstract}

Keywords: Street Art, Creativity, Singularity, Urban Environment. 


\title{
Estudio Fotográfico del Arte Urbano: de la Aventura Prohibida al Compromiso Político
}

\begin{abstract}
Resumen:Las expresiones semióticas se constituyen por imágenes cargadas de valores y conceptos que están ampliamente presentes en el medio urbano y se han convertido en un fenómeno cultural de la actualidad. El arte de calle es una de las formas de semiótica que tiende a modificar el cotidiano social de la ciudad, embelleciendo, denunciando, o aun siendo incomprensible al transeúnte en general. Este estudio, partiendo de una perspectiva histórico-social, tiene el objetivo de indicar cómo las interferencias del arte urbano producen cultura e influencian la construcción del proceso societario. Los datos fueron recolectados por medio de 100 fotografías tomadas en municipios de Río de Janeiro entre los meses de marzo de 2013 y abril de 2015 y entrevistas con 17 artistas callejeros, tratadas por el análisis de sentido. Los resultados sugieren que aunque existe una codificación semiótica dominante en los espacios urbanos, la actuación de los artistas callejeros expone innumerables otras voces sociales que presentan nuevos lenguajes artísticos y actuaciones en el espacio público que funcionan como micropolítica. Se concluye que el arte de calle influye en la sociedad y ayuda a desnaturalizar la semiótica capitalista, democratizando las ciudades y favoreciendo que se entiendan los lugares públicos como de uso común.
\end{abstract}

Palabras clave: Arte de Calle, Creatividad, Singularidad, Ambientes Urbanos.

\section{Introdução}

Na pós-modernidade ocorreu uma valorização e multiplicação dos signos de comunicação de forma que o ser humano passou a conviver com inúmeras e diferentes linguagens. Para Santos (1997), a tendência à propagação e diversificação de signos tem se tornado um fenômeno cultural e expressões semióticas tornaram-se endemicamente presentes no cotidiano social. Para Lotman (1996), qualquer produção de comunicação se estabelece em um determinado local, nos espaços semióticos. Assim, pela intervenção humana, cada objeto colocado em determinado espaço segue uma determinada lógica em que a forma se conecta com conteúdo (Santos, 1996). As expressões semióticas, portanto, congregam imagens, conceitos e valores de acordo com a organização e produção semiótica em seu espaço. As expressões semióticas tanto podem reforçar determinados sentidos, quanto construir novos significados sociais. Por um lado, a espécie humana necessita de signos de comunicação "[...] para entender o mundo, à si mesma e às pessoas com as quais mantém relações [...]" (Silva, 2003). Por outro lado, quando a produção semiótica apresenta aspectos hegemônicos, esta tende a gerar um aprisionamento cultural através do ofuscamento e naturalização de determinado conteúdo (Guattari, \& Rolnik, 1986).
A arte de rua é uma das formas de expressão semiótica presentes no cotidiano social e urbano que tem sido tema de pesquisa em inúmeros países (Campos, 2013; Prosser, 2006; Rink, 2013; Strapasson, \& Silva, 2011). Estudos analisam as diferenças entre as estratégias da pichação e do grafite (Prosser, 2006; Tavares, 2010) ou a capacidade criativa e de resistência que estas práticas estabelecem aos efeitos negativos do sistema capitalista (Caldeira, 2012; Furtado, 2012; Rink, 2013; Santos, 2010a; Silva, 2004). Ainda que a arte de rua esteja agora conquistando espaço no mundo acadêmico, há poucos estudos sobre a construção da subjetividade dos artistas de rua nos processos societários. A importância social e acadêmica deste estudo está em apresentar elementos semióticos relacionados às novas formas de utilização e vivências dos espaços urbanos e, assim, expor outras possibilidades de atuação, estética, ética nestes lugares; e, ainda, produzir material acadêmico relevante de modo a renovar a forma de se conceber e pensar sujeitos sociais e metrópoles.

Usualmente a cidade é uma área de comunicação com uma estruturação semiótica feita de signos de placas de trânsito, luzes de semáforos e diversos objetos de propaganda, dentre outros elementos. Alguns destes signos de comunicação conferem funcionalidade ao espaço e precisam ser rapidamente captados pelos transeuntes. Outros, como a propaganda, "pre- 
cisam" de visibilidade de modo a chamar a atenção para o consumo. A arte de rua também está presente em muros, fachadas e paredes das metrópoles, ainda que não sejam previstos pelo Estado e pela organização urbana. Evidencia-se, portanto, dois tipos de produção semiótica que ocorrem nos espaços públicos, o primeiro considerado "dominante", por ser acolhido, consumido e estar naturalizado no pensamento social; o segundo é "não dominante" por estar no domínio da ruptura, da surpresa e, consequentemente, da angústia, por isso, na maioria das vezes, causa algum tipo de repúdio social e institucional (Guattari, \& Rolnik, 1986).

Guattari e Rolnik (1986) consideram que grande parte da produção semiótica dominante da atualidade é fabricada com a finalidade de favorecer ao sistema capitalista. De acordo com estes autores, para além da comunicação dominante realizada nos espaços semióticos, existem minorias que atuam nas áreas públicas movidas pelo desejo pessoal e coletivo. Na perspectiva destes autores, estas pessoas produzem tanto processos de singularização, quanto de subjetividade, ou seja, criam micropolítica que subverte o direcionamento dado aos espaços públicos na atualidade.

Ainda que signos da arte urbana existam em larga escala nas metrópoles, são elementos semióticos não dominantes, uma vez que não são programados para estar no contexto urbano. Também não está naturalizado o direito destes atores sociais atuarem no espaço público. A arte de rua apresenta elementos semióticos sem uma finalidade específica, existe, portanto, uma variedade de expressões que retratam sensibilidade estética e singular dos artistas de rua. Estas intervenções apresentam uma diversidade semiótica com matrizes dialógicas carregadas de historicidade, signos coletivos e o desejo de expressão e comunicação que pode instigar o transeunte de diversas maneiras, seja pela ironia, seja pela criatividade (Rink, 2013). A arte de rua geralmente apresenta "[...] com bom humor o contexto social, político, ambiental e surreal de nossa 'insana' sociedade. Mostrando uma nova estampa, para lugares comuns e por vezes marginalizados pelo contexto urbano existente" (Assis, 2012, para. 3).

As diversas formas semióticas exibidas na área urbana são uma forma de produção subjetiva, visto que contêm uma diversidade de informações e valores que participam do cotidiano social. Segundo Ferreira Neto (2004), os arranjos urbanos enquanto produções subjetivas são pouco estudados pela Psicologia, ainda que a História da Psicologia tenha em
Wundt (1832-1920) a concepção de consciência constituída pela "experiência imediata" em que sensação e sentimento formam uma unidade. Ferreira Neto (2004) acrescenta que o conceito de experiência imediata em Wundt atribui à subjetividade elementos tais como "[...] emergência histórica de processos, não determinados pelo social, mas em conexão com os processos sociais, culturais, tecnológicos, midiáticos, ecológicos, urbanos, que participam de sua constituição de seu funcionamento" (Ferreira Neto, 2004, p. 4). Para este autor, o sujeito é compreendido a partir de sua configuração e construção histórica, ou seja, cada pessoa vivencia e se constitui pelo modo de subjetivação que se constrói na modernidade. Pela percepção, não apenas se observa a realidade, esta passa a fazer parte de nossa psique, de nosso ser.

Em Vigotski (1984/2011) já era possível perceber como a psique individual se constitui através de sistemas simbólicos em uma dada sociedade. $\mathrm{O}$ autor vai além, ao indicar a importância da renovação simbólica na construção de novas realidades sociais. Para este autor, é na produção de símbolos sociais que reside o germe da criatividade humana e das transformações culturais. Molon (2003), corroborando a perspectiva de Vigotski, afirma que, embora a cultura seja determinante para a formação do sujeito, a criatividade humana prevalece: "[...] a despeito de todas as forças históricas em contrário” (p. 11). A atividade criadora do ser humano estrutura-se na sua capacidade de imaginar e de criar novas situações, inventando o presente e construindo e o futuro (Vigotski, citado por Molon, 2003).

Atualmente a arte de rua, especialmente o grafite, tem mais aceitação social e é autorizada a figurar em alguns espaços públicos. Não raro, alguns grafiteiros são convidados para pintarem em determinados espaços, existindo até leis que protegem o grafite e estipulam áreas para sua execução, como a legislação municipal de Niterói. Ainda assim, o grafite não tem um espaço assegurado. Giordano (2014) afirma que grafites são apagados em Niterói sem maiores justificativas, contrariando a legislação municipal. Assim também acontece em outros estados, como São Paulo, que é referência de grafite no mundo, porém enormes painéis de grafite localizados na Avenida 23 de Maio foram apagados a mando do prefeito Dória em janeiro de 2017, sem mesmo a realização de uma consulta pública. Este fato indica que o grafite, em muitas situações, ainda é uma forma de produção semiótica não dominante. 
Os espaços públicos em cada ocasião produziram determinados significados, tal como na época da industrialização, entre os séculos XVIII e XIX, ou no início do século XX com o capitalismo de tipo fordista (Verás, 2001). Para Müller (2004), o foco do planejamento mais recentemente passou a nortear a inclusão do cidadão e da vida que ele leva naquele espaço, ou seja, inclui-se nos planejamentos urbanos a participação da comunidade. Verás (2001) avalia que, apesar de efetivamente existirem questões sociais e de cidadania que devam ser levadas em consideração no planejamento urbano, na prática, o espaço público é disputado politicamente. Araújo (2013) argumenta que é o neoliberalismo que tem exercido mais forte influência neste planejamento que recai tão somente na relação entre a cidade e o mundo globalizado. De acordo com o autor, o intuito é unicamente o de atrair investimentos que tornem um determinado local mais interessante ao capital, seja através do turismo ou da industrialização. Para o autor, os investimentos são direcionados para a valorização do espaço da cidade em que se encontram as classes mais altas da sociedade.

Para Verás (2001), por meio da codificação dos espaços das metrópoles produz-se uma sujeição econômica do indivíduo ao capital. Assim, a ampla disseminação de propaganda nas cidades é um indicativo dessa forte configuração neoliberal que, além de enfatizar uma ideia de indivíduo visto apenas como consumidor, naturaliza um tipo de concepção de que as empresas, com fins lucrativos, podem apropriar-se dos lugares públicos. Nas discussões de Müller (2004) sobre a semiotização nas áreas públicas de Curitiba observa-se uma diminuição da diversidade semiótica necessária para tal ambiente, assim como nos usos dos espaços. A autora aponta que a produção semiótica visa obter visibilidade e direcionar o olhar do transeunte para o mercado de consumo, e não há diversidades de signos capazes de provocar reflexão nos transeuntes. De acordo com Verás (2001), a codificação dos espaços públicos torna o capital "um poder tanático que destrói o espaço fugidio da cidade, convertendo-o em metrópole impessoal e sem memória. Por isso, os momentos revolucionários seriam desobediências à História" (Verás, 2001, p. 1).
Fica, portanto, evidente que a sociedade, pela via da produção semiótica, naturalizou o lugar do transeunte submetido à lógica do capital, visto que poucas pessoas manifestam repúdio a tal situação. Arendt (2004) indica que foi o esvaziamento da esfera pública e a incapacidade de ações políticas pela busca do bem comum, a ausência de intercâmbio e de pluralidade de ideias que possibilitou a ocorrência do Totalitarismo, tanto na Alemanha como em outras partes do mundo. A produção de arte de rua se torna uma ação fundamental, visto que, além de indicar a existência de não submissão à lógica estabelecida nos meios urbanos, possibilita a ocorrência do intercambio e criação de ideias.

Para Guattari e Rolnik (1986), qualquer forma de luta contra signos semióticos hegemônicos é importante. De acordo com os autores é no nível "infrapessoal" e na maneira como se vive cada relação e cada desejo que se torna possível uma "revolução molecular", que tende a ganhar repercussão na escala social. Assim, a produção de arte de rua pode ser percebida como um tipo de arte revolucionária, pois suas intervenções constituem uma forma de desobediência ao pensamento social dominante.

É fundamental ter a concepção de que as cidades podem e devem ser reconfiguradas constantemente, de acordo com as atuações dialógicas dos sujeitos e suas inter-relações. Esta ideia de transfiguração do ambiente urbano é importante no trabalho de Habermas (1990) e Santos (2010), ao considerarem que os ambientes públicos não existem previamente à sociedade, mas são construídos por ela e, por isso, devem ser politicamente conquistados. Estudando as produções artísticas e as interferências da arte urbana na produção cultural e na formação da sociedade, pode-se notar ações comunicativas que tendem a abrir espaços para o debate e para a renovação simbólica pautados pela diversidade das intervenções urbanas.

O objetivo deste estudo é indicar como as interferências da arte urbana produzem cultura e influenciam a construção da subjetividade nos processos societários. Por isto, investiga-se "lugares de identificação" $\mathrm{e}$ "lugares identitários"2, que, segundo Sawaia (2008), devem ser prioridade em um estudo no campo da Psicologia Social. Para a autora, o valor de se pesquisar estes luga-

\footnotetext{
${ }^{1}$ Os "lugares de identificação" são aqueles que potencializam a ação individual em favor do bem comum e da ação coletiva em prol da felicidade individual (Heller, 1977).

2 "Espaço identitário", segundo Augé (1992/2005), tem a característica de ser relacional e histórico, opondo-se aos "não lugares” produzidos na modernidade, a qual constrói espaços codificados para o consumo.
} 
res dá-se pelo fato de estes abarcarem atuações singulares, capazes de produzir subjetividade e enriquecer o desenvolvimento cultural da sociedade. A opção por utilizar fotografias feitas no campo de pesquisa visa oferecer referências conceituais e imagéticas que possam criar marcas tanto para a academia quanto para a sociedade, relativas às novas formas de utilização dos espaços públicos e das vivências dos artistas de rua.

\section{Metodologia}

Neste estudo investigou-se a arte de rua por meio de 100 fotografias feitas entre o mês de março de 2013 e o mês de abril 2015 nas cidades de Niterói, São Gonçalo e Rio de Janeiro (RJ). Foram feitas entrevistas semiestruturadas com 17 artistas de rua participantes do estudo com idades entre 18 e 60 anos; foram entrevistadas quatro mulheres (duas de 20, uma de 35

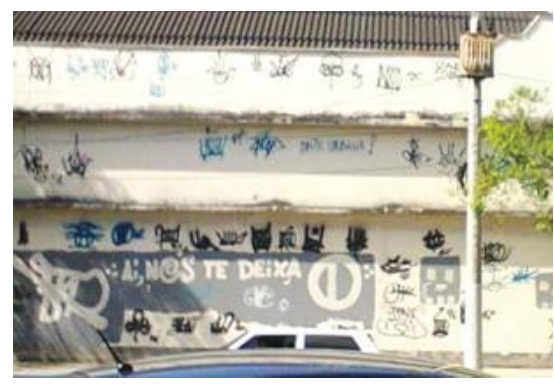

Foto 1: Rua Feliciano Sodré, Niterói (RJ), 2013

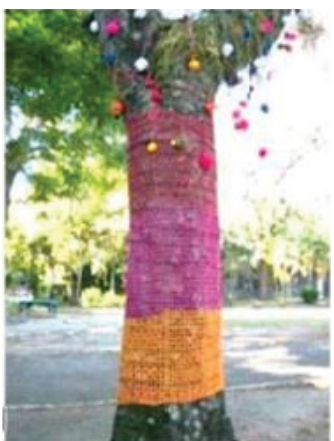

Foto 4: Praça no centro da rotatória da Rua Quintino Bocaiúva, em São Francisco, Niterói (RJ), 2013

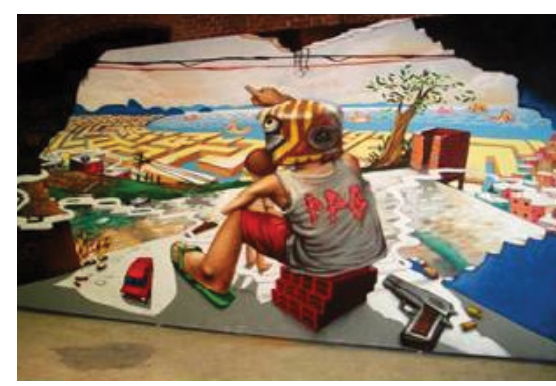

Foto 2: Art Rua, Gamboa (RJ), 2013

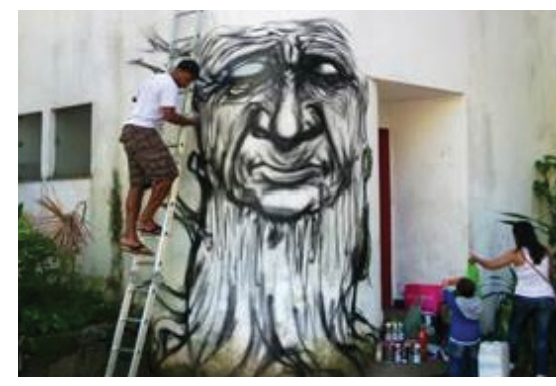

Foto 3: Campo de São Bento, Icaraí (RJ), 2013

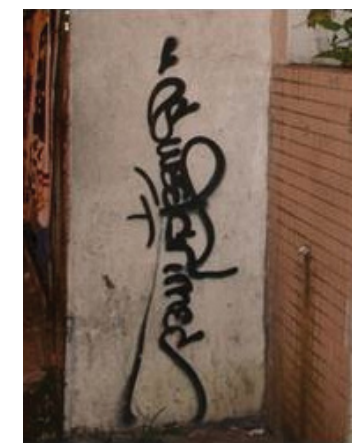

Foto 5: Jardim Botânico (RJ), 2014

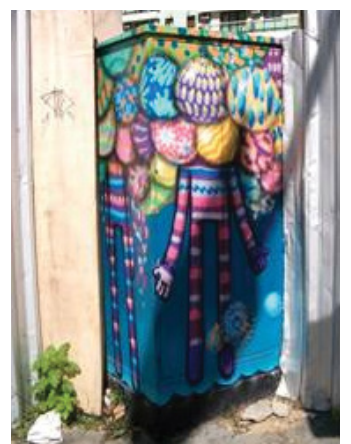

Foto 6: Jardim Botânico (RJ), 2014

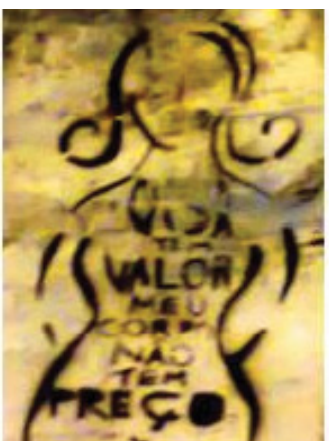

Foto 7: "a vida tem valor meu corpo não tem preço". Ladeira de Santa Teresa (RJ)
Figura

Amostragem de arte de rua de municípios do Rio de Janeiro.

\section{Definição}

Diferenciação entre pichador e grafiteiro

Experiência pessoal de formação na arte de rua

Cuidar da cidade através do seu embelezamento

Críticas que expressam preocupações sociais

Quadro

Modalidades temáticas da arte urbana. 
e outra de 55 anos) e 12 homens (sete de 18 a 20 , cinco de 21 a 30 anos, quatro de 31 a 40 anos e um de 60 anos). Também houve anotações de campo. O critério de seleção dos participantes foi aleatório e ocorreu junto àqueles que produziam e conviviam cotidianamente com a arte de rua. Todos os participantes assinaram o Termo de Consentimento Livre Esclarecido.

A fase inicial e exploratória da pesquisa envolveu fotografias e conversas informais com artistas de rua. A cada fotografia tirada foram feitas anotações de datas, horários e comentários relacionados, como o exame da intenção e motivação da criação da imagem fotografada. As fotografias, juntamente com o que se apreendeu das conversas informais e das anotações do campo de pesquisa, foram analisadas por meio do método de análise de sentido (Vigotski, 2004; 2005). Para Vigotski, tratar os dados pela análise de sentido é examinar eventos semânticos formados através de relações sociais, construções históricas e culturais. Ao final desta análise foi possível identificar e definir quatro categorias: a) Pichação como marca pessoal; b) Iniciação na arte de rua; c) Estético-cultural; d) Contestação crítica social.

Em seguida, elaborou-se o roteiro de entrevistas "centrado no problema" (Rocha-Coutinho, 1994) e balizado pelas categorias, que visou aprofundar as questões levantadas na exploração inicial. O Roteiro de Entrevista com os artistas de rua foi construído a partir de dois eixos e perguntas balizadoras: 1) Qual a importância da arte da rua em sua perspectiva? e 2) Você se comunica com transeuntes enquanto faz suas intervenções urbanas? As entrevistas foram gravadas e degravadas (transcritas) na íntegra e também tratados pela análise de sentido.

\section{Resultados e discussão}

Por meio das fotos foi possível constatar que a cidade está repleta de variados tipos de arte de rua: estátuas vivas, malabaristas em semáforos, grafites, lambe-lambes (cartazes), estênceis e grafites feitos em paredes, hidrantes, caixas de luz, árvores e postes, dentre outros. A Figura apresenta uma amostra das fotos selecionadas como representativas do estudo.

A categorização das modalidades temáticas da arte urbana da fase exploratória das fotografias e das conversas informais é apresentada no Quadro.

Doravante apresenta-se a discussão de cada categoria com alguns ilustrativos segmentos de entrevistas - apresentados entre parênteses com "S." seguidos de identificação numérica de cada participante.

\section{a) Pichação como marca pessoal}

O maior número de ocorrências encontradas na área urbana foi de pichações (Foto 1 da Figura 1). A maioria destas marcas não visa criar um tipo de conteúdo que facilite sua compreensão lógica ao público. Estas geralmente são formas de assinaturas pessoais, em que marcas específicas determinam a autoria. Ainda que se encontrem pichações em qualquer lugar de uma cidade, muitas dessas expressões localizam-se em áreas de difícil acesso, como no alto de edificações, e são chamadas de "voadores" pelos artistas de rua. Encontrar pichações voadoras na arquitetura urbana, em geral, é um indicativo de que alguém subiu, escalou e fez uma inscrição dando visibilidade à sua marca.

A Foto 1 (Figura 1), além das pichações voadoras apresenta diversas formas de picho, desde inscrições feitas próximas ao chão até no alto, provavelmente realizadas por diferentes pichadores, considerando-se as múltiplas assinaturas ou modos de expressão encontrados. Esta diversidade vista nas fotos fica evidenciada nas entrevistas que indicam diferentes maneiras de qualificar as pichações, reconhecidas como uma marca, sigla ou assinatura, de interpretação restrita àqueles que são artistas de rua.

Pichação é uma marca, você vai lá e faz uma assinatura. Na verdade são marcas, normalmente em preto, são aqueles rabiscos. [...] Tem um código que só quem é da rua vai saber ler ali a pichação, ela tem uma característica própria [...] (S. 12).

Os relatos revelam que a pichação é valorizada desde os anos 1990, e sua qualidade é determinada pela capacidade de um pichador tornar sua sigla bem visível, identificável e multiplicada quanto mais possível. Pichadores que conseguem fazer um grande número de siglas no ambiente urbano passam a ser reconhecidos entre seus pares, tornando-se importantes para um determinado grupo.

Alguns participantes fazem uma leitura semiótica destas marcas apoiando-se na história da arte: "pichação [...] então parece muito, às vezes, com uma caligrafia japonesa ou com Amílcar de Castro no final da carreira, ele faz os desenhos também bem gráficos" (S. 12). Para Bakhtin (citado por Faraco, 2011), a estética tem raízes na história e na cultura, de onde extrai sentidos e valores de uma determinada "atmosfera axiológica”. Ao comparar a pichação com a caligrafia japonesa ou determinadas obras do famoso artista 
plástico Amílcar de Castro, os artistas de rua reforçam suas posições axiológicas e atribuem valor(es) às suas práticas. Estes valores, porém, se diferem da "atmosfera axiológica" atual, em que não se confere qualquer valor à pichação em si.

Este abismo axiológico que existe entre a pichação e os valores atuais é difícil de ser compreendido em um primeiro momento, visto que a pichação já tem sido explorada em pesquisas que datam desde os anos 1970 em Sociologia, Antropologia e Psicologia (Carvalho, 2013). Mesmo com quase 50 anos de pesquisas sobre o tema, até hoje os pichadores continuam, de certa forma, sendo socialmente invisíveis. Este fato talvez possa ser explicado, dado que certos estudos acadêmicos reforçam ideias errôneas sobre a pichação, como, por exemplo, encontrou-se em Marcheri e Rosseto (2014), que afirmam que pichadores são adolescentes com tendências a entrar para o mundo da criminalidade. Estes autores produziram narrativas definidoras do que seja um pichador, porém o cenário da pichação é bem mais complexo. Segundo Sawaia (2008), a Psicologia Social deve produzir formas de "desfetichização do sujeito" e, para que isso ocorra, é preciso conceber a sociedade tanto pelo prisma do desejo individual, quanto pelas das relações de poder estabelecidas em dada cultura. Ao se analisar dimensões relacionais, culturais e históricas que influenciam as pessoas, segundo a autora, é a única forma de escapar de tais narrativas definidoras que desprezam em seus estudos as forças que a própria história e os mecanismos sociais exercem sobre cada pessoa.

Segundo Carvalho (2013), ocorre uma estigmatização e marginalização da prática da pichação quando não se considera nas pesquisas o fato de que a comunicação humana é um fenômeno muito antigo e universal. Conforme o autor, onde existe vida humana existem processos de comunicação. Por este motivo, a ocorrência da pichação revela a existência de outras realidades sociais que devem ser estudadas.

Will (2015) faz críticas a um tipo de atribuição que tem sido dada pela mídia e inúmeros setores da sociedade aos jovens das favelas cariocas, de uma inclinação para a criminalidade. Para a autora, a criminalização do jovem pobre e, geralmente, preto não se baseia na realidade, e sim em estereótipos que são construídos propositalmente. Esta mesma lógica tem sido aplicada aos pichadores, visto que o tratamento dado a eles parece reforçar a ideia de que são elementos perigosos, como pode ser visto a seguir: "no Brasil, o pichador, ele roda, ele é preso... ele tem que pagar uma fiança, pra não ficar na cadeia, no serviço comunitário. Isso é a parte bonitinha que o Estado mostra. Mas, na verdade, existe espancamento, tortura e morte" (S.1). E para reforçar o entendimento da criminalização e mesmo tentativas de extermínio dos pichadores, os participantes mostraram em seus corpos marcas de tiros que levaram de policiais ou de espancamentos. Isto, segundo eles, é usado como forma de inibir a pichação, porém revela a invisibilidades e o enorme desrespeito conferido a estas pessoas.

Os nossos resultados evidenciam um cenário bem diverso, onde pichadores são pessoas regularmente inseridas na sociedade através das profissões que exercem. Os participantes relatam que o início da pichação acontece na escola, este fenômeno é visto como um tipo de vício na época da adolescência em função da adrenalina gerada durante cada ato de pichação. O reconhecimento entre os colegas, amigos e comunidade também é fator importante. Na fase adulta, embora muitos pichadores já tenham uma profissão regular, continuam a atuar anonimamente. Também fica claro que não é a classe social que determina a gênese de um pichador:

Meus amigos, que são da pichação [...] podem ser classe média, classe média alta, eu conheço história de pichador, que é advogado... eu conheço advogado, conheço engenheiro, dentista, policial, arquiteto, que começaram a pichar quando tinham 14, 15 anos na escola e o vício não passou (S. 1).

Este resultado está em conformidade com os estudos de Carvalho (2013), que também não qualifica a pichação "como um comportamento juvenil desviante [...]” (p. 12).

A pichação, porém, é muito mais do que fazer inscrições no alto dos prédios. Foram notados aspectos relacionados à sociabilidade e à filantropia na narrativa dos participantes: "Aí, começamos a fazer mutirões, juntar pessoas pra doar sangue. Juntamos pessoas para doar roupas, pra fazer trabalhos sociais e basicamente e também pra trocar papéis. Papéis com nossas marcas [de cada pichador]" (S. 17).

Se, por um lado, a sociedade e o Estado veem a pichação como crime, por outro lado, existe um reconhecimento dado aos pichadores por seus pares. 
Mesmo havendo repressão policial, isto não se torna o fator principal para a pessoa se tornar ou não um pichador. A narração do participante revela isso: "[...] eu só não fui pra pichação porque eu gostava de desenhar e também porque eu tinha medo de altura" (S. 10). Assim, tornar-se grafiteiro ou pichador está mais relacionado a algumas habilidades e características pessoais. A opção por ser um pichador indica que o sujeito tem coragem e ousadia para escalar lugares altos, o que acaba por tornar a pichação uma atividade excitante, ao mesmo tempo, arriscada para a vida. Um fator inibidor da pichação vem a ser o risco da escalada, que, por sua vez, é fator de respeito entre pichadores e grafiteiros: “[...] tem a escalada, subiu pelas janelas e tudo... Tem um outro dado, que é a adrenalina, você não pode cair lá de cima e alguns caem. O cara tem que ser um Ninja. Quando ele me mostrou uma foto do prédio [que pichou] tem que respeitar, porque marcou mesmo" (S. 12).

Alguns pichadores revelam que nem suas famílias, cônjuges e filhos sabem de suas práticas como pichadores. O relato a seguir é ilustrativo: "tem gente que sai sozinho e anda sozinho, com lata de spray dentro da bolsa o dia inteiro, no trabalho e, sei lá, quando dá ele picha. Não sai de noite, tem gente que não sai, porque a esposa não sabe" (S. 7).

Os participantes dizem que comumente são criticados como depredadores do patrimônio público. Seus relatos, no entanto, indicam que eles ressignificam o sentido da depredação, ao atribuírem o abandono do patrimônio público pelo Estado como uma verdadeira forma de depredação. Eles dizem que onde há muita pichação, o patrimônio público já havia sido abandonado e depreciado pelo Estado.

Primeiro que o grafite não depreda nada e só tem pichação onde já tá depredado... Aí você olha tem um Castelinho aqui no Gragoatá [Niterói-RJ], ele tá todo pichado, agora o abandono do patrimônio é o que é depredar, e tem o abandono do Estado que abandona o prédio, prédio que está tombado. Tem uma discussão na geologia... O prédio está todo pichado, tá pichado porque está abandonado, sem porta, sem janela, já com problema na estrutura (S. 12).

A pichação, portanto, além de ser um "processo de comunicação visual e não-verbal onde o emissor emite uma mensagem codificada em forma de assinatura esti- lizada" (Carvalho, 2013, p. 11), também pode servir para denunciar o abandono do espaço ou patrimônio público.

Os pichadores apropriam-se "[...] de ideologias que regem a sociedade capitalista, como os sistemas de comunicação e marketing e a competitividade mercadológica" (Ceará, \& Dalgalarrondo, 2008, p. 1). Igualmente como a propaganda, são incontáveis as pichações encontradas nas áreas urbanas. Ainda assim, estas marcas não se tornam formas dominantes de produção semiótica. Ao contrário, nos estudos de Araujo (2005), Carvalho (2013) e Souza (2007), a pichação tem sido marcada fortemente pela repressão que os pichadores sofrem.

Oliveira (2009) considera que foram as bases históricas que produziram a dificuldade que se tem hoje de valorização da polifonia urbana. Esta dificuldade impede discernir entre o que efetivamente é crime e o que é arte. Para Gombrich, (2007), conhecido teórico da história da arte do século XX, a arte deve ser concebida como expressão da subjetividade e percepção do mundo pelo artista. Em outras palavras, o autor considera a arte como uma expressão de um tipo particular e singular de conhecimento, de desejo, de experiência manifestada através de alguma forma de linguagem artística. Se este conceito fosse tomado em consideração pelas autoridades talvez fosse possível identificar a pichação como uma forma de arte, ao invés de um crime.

A pichação apresenta características diferentes do grafite, que, por sua vez, já obtém maior aceitação social. No entanto, revelou-se nos relatos que muitos grafiteiros que hoje são famosos tiveram seu primeiro contato com as latas de spray na condição de pichadores e, como tal, se tornaram conhecidos primeiramente entre aqueles que admiravam sua capacidade de espalhar sua marca no alto das edificações.

O Fábio [Ema, conhecido grafiteiro carioca,] era pichador [...] na época daquela década de revolta [1995], né!? Porque foi o auge da pichação. E em São Gonçalo, o Fábio era um dos caras, muito influente. Porque o que ele fazia, todo mundo queria fazer [...] ele era um dos caras com uma das siglas mais famosas, então toda a garotada queria estar junto com o Fábio, queria estar junto com [Marcelo] Eco [ex-pichador e hoje também é grafiteiro famoso do Rio de Janeiro] (S. 7).

Os pichadores também podem ser percebidos fora da polaridade "crime ou arte" através do conceito 
de singularidade elaborado por Guattari e Rolnik (1986). Para estes autores, pessoas que criam modos próprios de existência e reconfiguram continuamente a forma de produção de subjetividade dominante no mundo do capital, produzem formas singulares de existência e se diferenciam de padrões hegemônicos de atuação no cotidiano social.

\section{b) Iniciação na arte de rua}

Os participantes relatam que, no conjunto da arte urbana, o grafite possui mais visibilidade social, o que se torna um fator motivacional para o aprendizado de sua técnica. Os dados apontam também que a iniciação no grafite acontece em diferentes contextos, envolvendo diversos tipos de pessoas, idades, áreas e níveis sociais.

Segundo os participantes, existe no Rio de Janeiro uma oferta de cursos desta modalidade de arte de rua em algumas escolas, em projetos educacionais, centros culturais e espaços criados pelos próprios grafiteiros. A partir dos relatos colhidos, descobriu-se que o grafite também é utilizado em projetos governamentais. Esta é uma forma de se desenvolver atividades estimulantes ao aprendizado dos jovens e proporcionar um enraizamento identitário (Brasil, 2013). Ainda de acordo com o Ministério da Educação (MEC) (Brasil, 2013), tais projetos visam integrar cultura, arte e sociedade. Os entrevistados relatam que iniciativas como estas fizeram a diferença para eles.

Eu fui convidado a participar... do governo e tal... de causas mais sociais... A comunidade na escola e aí, tem justamente essa problemática, da maioria das vezes dos garotos de famílias desestruturadas, sem mãe, sem pai, ou só a mãe, aí precisando trabalhar, ficando o dia inteiro na comunidade, rodando na favela, fraco, sendo usuário de drogas. Aí a escola tinha uma preocupação em outras atividades. A escola foi uma grande diferença (S. 10).

A paulatina institucionalização do grafite em diversos espaços sociais é percebida pelos grafiteiros, isto também faz com que algumas pessoas se interessem em aprender sua técnica: "[...] Fiquei sabendo da exposição [de grafite], aí comecei a me interessar mais; aí um dia soube que ia ter o curso [de grafite no Centro Cultural Paschoal Carlos Magno]” (S. 9).

Lazzarin (2007) considera que "o grafite, como movimento social e artístico, cruza o território mar- ginal em direção à institucionalidade; às vezes, como forma de inserção social, outras, como simples modismo..." (p. 63). Alguns participantes revelam que o grafite desfruta de bastante visibilidade na sociedade e pode ser um dos atrativos para as pessoas se interessarem e iniciarem nesta forma de linguagem artística. Outros participantes relatam que agem movidos apenas por satisfação pessoal, sem interesse em um reconhecimento por parte da sociedade.

Eu pinto pra mim, não ligo se ninguém achar bonito, não ligo se as pessoas acharem feio, eu não ligo para nada disso, eu não tenho interesse de participar de nenhum projeto social, não tenho interesse em ganhar dinheiro com isso, mídia, nada, sabe, se acontecer é ótimo, mas se não acontecer não vou ficar triste, pois não estou esperando (S. 4) [grifo nosso].

Neste relato fica evidente o quanto este ator social tem conhecimento de que existem inúmeras possibilidades sociais para o artista de rua que se utiliza do grafite, embora a fala expresse um sentido de indiferença quanto ao impacto de sua produção de arte de rua ou aprovação pela sociedade a suas atuações urbanas. A inclusão das palavras "se" e "mas", nos leva a pensar se o ganho de reconhecimento social não seria um desejo não revelado pelos participantes. Nos relatos dos participantes pode-se identificar o impacto que o grafite exerce sobre outras pessoas: "Você faz um grafite bom e acaba todo mundo lembrando, fica na memória de todo mundo..." (S. 5) e "Você fica reconhecido..." (S. 8).

Os artistas iniciantes entrevistados também relataram a surpresa com o resultado de seu primeiro grafite e a satisfação em grafitar nas ruas por causa da sensação de ficarem em evidência na sociedade: "Ninguém imaginava que ia ficar aquilo. Acho que o maior prazer foi olhar [para o grafite] e falar assim: 'cara foi eu mesmo que fiz?' [...] O pessoal queria até levar o muro..." (S. 14). Já outras narrativas indicam que fazer grafite e principalmente aprender com grafiteiros aumenta o sentido de liberdade de expressão: "eu sou muito presa, eu acho que grafite é muita liberdade. Ter entrado para o curso me deu mais liberdade, pra conseguir fazer algumas coisas, eu acho que grafite é muito isso, muito liberdade" (S. 3). Existem aqueles participantes que revelam uma necessidade intrínseca de se apropriar desta linguagem: “[...] é uma 
coisa que eu preciso disso [aprender técnicas e modos de grafitar], até isso ficar introjetado em mim" (S. 5).

Além de grafitar nas ruas, os atores sociais revelam que também fazem produção musical, poesia e participam de atividades como "Roda Cultural" ${ }^{3}$ e slackline $e^{4}$ Isto indica que existe uma percepção destes atores sociais sobre a arte de rua como um veículo que integra múltiplas dimensões de expressões e possibilidades artísticas no cotidiano. Na prática, diversas técnicas se integram, bem como aspectos de sociabilidade:

[Na arte de rua] tem tanto o grafite como o lambe-lambe que é colar cartaz. Eu tenho meu coletivo com uns amigos meus; não só grafite, a gente gosta de música e de vários tipos de temas. Tem poesia... Então, é assim: ah, vou pintar hoje, ah, vou fazer um churrasco, pra gente, né!? Eu fiz uma máscara de papel-machê, pintei, aí o outro amigo pegou botou a roupa tiramos a foto e colamos no colégio (S. 9).

Outro aspecto a ser ressaltado é uma errônea percepção da sociedade sobre a idade dos grafiteiros e daqueles que se interessam por aprender a produzir a arte do grafite. A sociedade percebe $o$ ato de grafitar como sendo relacionado aos jovens; os dados da entrevista, porém, mostram uma realidade diferente. Muitos profissionais que se iniciaram na juventude no grafite e/ou na pichação continuam atuando com a arte de rua na vida adulta; e indivíduos mais velhos também têm se tornado grafiteiros. De modo geral, para estas pessoas, o aprendizado da linguagem do grafite é um importante canal para produzir questionamentos em sociedade. Para alguns, esta concepção de uma técnica que possibilita questionar a sociedade é tão importante quanto o desejo de ir pintar na rua e descobrir como é viver esta experiência: "Eu venho crescendo muito, porque somo esta experiência de artista [plástico], esta experiência de questionamento, né!? [...] Me interessa a linguagem do grafite que vai me ajudar a produzir a imagem... Mas eu fiz o caminho de ir para a rua pra ver o que é a rua" (S. 2).

Observa-se que o grafite, assim como a pichação, aglutina pessoas de diferentes idades e grupos sociais que se interessam em aprender a técnica e, acima de tudo, atuar e pintar nas ruas. A iniciação na arte de rua em relação aos mais jovens é diferente dos mais velhos; os primeiros não demonstram interesse em produzir diálogos com a sociedade ou críticas sociais. A iniciação na arte de rua para os mais jovens indica uma necessidade de se tornar conhecido em um grupo social mais próximo, como o do colégio, por exemplo. É, portanto, a interação social e o reconhecimento dos pares que pauta as primeiras experiências dos jovens artistas de rua. Os mais velhos, por outro lado, têm mais interesse em questionamentos de assuntos sociais, e também pelo desenvolvimento de uma maior liberdade de expressão.

\section{c) Estético-cultural}

A penúltima categoria chamada de "estético-cultural" foi constituída a partir de fotos que destacam o embelezamento do espaço público. Existe uma grande variedade de formas de arte de rua incluída nesta categoria, desde o tricô em árvores (Foto 4, Figura 1), grafites diversos e também um tipo de pichação que não se repete e se encaixa na paisagem embelezando determinada área da cidade (Foto 5, Figura 1).

Nesta modalidade artística, o cuidado com o meio urbano desponta como ponto de partida e como objetivo final. Nas entrevistas foi possível observar como os participantes consideram os espaços urbanos como se fossem museus ou galerias a céu aberto. Isto é, como um local em que existe liberdade para exibir sua arte: "[grafite no muro] como um quadro de parede, como se estivesse em um museu público...” (S. 4).

As intervenções urbanas consideradas como produções estéticas podem ser encontradas em qualquer lugar no cenário urbano, inclusive em locais malcuidados e que não teriam praticamente nenhum atrativo se não tivessem aquelas intervenções artísticas. Os participantes dizem ter preocupações com o embelezamento de espaços descuidados pelo poder público: “[...] eu costumo inserir minhas expressões artísticas em espaços abandonados e ociosos" (S. 15).

Também foram detectadas situações em que a prática do grafite envolvia famílias (Foto 3, Figura 1), ou seja, não apenas o artista urbano em cena isola-

\footnotetext{
${ }^{3}$ Movimento que reúne diversas tribos/grupos do movimento hip hop e de cultura urbana em eventos que ocorrem semanalmente. Existem diversas batalhas (disputas) com rimas entre MCs (Mestres de Cerimônia). O encontro reúne grafiteiros, skatistas, DJs (Disc-Jockeys), poetas e dançarinos de break formando um grande coletivo.

${ }^{4}$ Fita elástica esticada entre dois pontos fixos, o que permite ao praticante andar e fazer manobras em cima dela.
} 
damente ou com seu grupo, mas com participação de sua família. A atividade de grafitar, portanto, gera microrrevoluções urbanas ao despertar um senso de pertencimento à cidade, inclusive pela sociabilidade. Em outras palavras, é uma das formas de micropolítica apontadas por Guattari e Rolnik (1986), que dão novos direcionamentos ao uso do meio urbano. Isto sugere que os artistas de rua têm reinventado a estética das cidades tanto por meio de seu embelezamento e cuidado com espaços públicos abandonados, quanto pela diversidade de usos dados a estes espaços. Esta ideia está no depoimento a seguir: “[...] fazendo grafite, que também me ensinou a rever a cidade como um local de uso público" (S. 4).

\section{d) Contestação crítica social}

O meio urbano está repleto de pinturas e inscrições de caráter crítico, que indicam formas de atuação dos artistas de rua que revelam preocupações e questionamentos relativos ao meio social. Algumas fotos da Figura 1 expõem diferentes modos de contestações: na Foto 2 há múltiplas leituras e reflexões sobre a desigualdade social; enquanto a Foto 7 apresenta uma silhueta de um corpo feminino com um escrito em seu interior: "a vida tem valor, meu corpo não tem preço", o que pode ser interpretado como uma estratégia política para se valorizar mais as mulheres ou também para opor-se a um tipo de cultura pautada pelo neoliberalismo.

A intenção de provocar questionamentos nos espaços públicos é considerada pelos participantes como um protesto em forma de arte: “[A arte de rua é] Importante! Muito! Mensagens em forma de desenho podem abranger até um movimento social. Podem libertar protestos artísticos" (S. 16) e "[o grafite é] uma grande ferramenta política" (S. 7). Estas expressões artísticas e críticas incomodam as autoridades e o poder público, visto que geralmente são rapidamente apagadas, como se revela a seguir: "Aquele da pilastra da ponte, fiz um moleque de cinco metros de altura. O moleque, pretinho e tal, e o dedo do meio apontado pra metade da cidade. Achei que não ia durar. Durou muito pra mim, sabe [três dias]" (S. 1). Ou seja, o grafite deixa de ser uma expressão artística para as autoridades quando revela um forte conteúdo critico ou considerado ofensivo, desta forma, mesmo um grafite em grandes dimensões é apagado facilmente.

Outras inscrições encontradas nos cenários públicos exibem temas ligados às bicicletas e ao estí- mulo à sua utilização em sociedade ou ao respeito que se deve ter em relação ao ciclista. Curiosamente, depois de serem encontradas incontáveis inscrições deste tipo, a Prefeitura de Niterói criou diversos corredores exclusivos para o uso de bicicletas no meio urbano no ano de 2015, já em uso.

Também existem relatos de políticos terem interesse em que grafiteiros façam seus retratos para campanhas políticas. Neste caso, é a postura crítica do artista de rua que revela sua forma de atuação: "Na época de eleição, surgiu uma proposta de eu fazer tipo ummm, aqueles time lapes. Não rolou, sabe. Porque o candidato finge que gosta de grafite, pra parecer que ele tem a cara mais progressista, mais jovem e tal" (S. 6).

Estas produções e atuações são formas de críticas ao status quo; estes atores sociais dizem que fazer arte de rua é uma forma de vandalismo e de desobediência à ordem estabelecida socialmente: “[...] grafite, ele é vandalismo, a essência dele é vandalismo, por isso que não tem diferença da pichação. Agora o grafiteiro ele pode fazer o serviço, receber dinheiro e tudo, mas ele continua com a mesma atitude quando era pichador" (S. 8).

O mundo da pichação, portanto, é o que cria o germe da desobediência tão valorizada pelos artistas de rua. Estes atores sociais gostam de manter esta atitude, independentemente de o grafite ser uma modalidade artística socialmente aceita em tempos mais recentes. É sentir-se uma espécie de pichador social o que move muitas intervenções gráficas produzidas sem autorização para figurar no espaço público. Isto também mostra como estes atores sociais são conscientes do poder das imagens e de suas atuações como forma de criar novos discursos sociais. Seja pelo grafite, pela pichação, pelo estêncil, ou por outras modalidades artísticas, a paisagem urbana como superfície para expressão tem revelado questões sociais que estão no domínio do desejo, do amor e da criação, assim sendo, colaboram na desconstrução de ideias sobre a própria finalidade dos espaços, tal como discutido por Guattari e Rolnik (1986). Assim, estes atores singularizam-se como sujeitos sociais através de atividades artísticas produzidas nos espaços públicos, recusando modos dominantes e preestabelecidos de atuação.

\section{Considerações finais}

Nesta pesquisa pôde-se perceber a forma como as cidades de São Gonçalo, Niterói e Rio de Janeiro estão sendo semioticamente e culturalmente recon- 
figuradas por meio da arte de rua. As análises e discussões sugerem a existência de um amplo campo de produção de arte de rua, a qual congrega inúmeras formas interação social, criatividade, ética, estética e política no cotidiano urbano. Foi possível identificar a intersubjetividade que ocorre nos ambientes em que artistas de rua atuam e produzem lugares de identificação e identitários. Este resultado contribui para o campo da Psicologia social e Psicologia Ambiental por identificar desejos e emoções individuais e coletivos que criam cultura, imbricando-se com as relações de poder nas cidades. O presente estudo tem consonância com uma pesquisa feita em São Paulo, em que "coletivos de artistas que emergem da periferia de São Paulo não se destacam somente pelas carências de seus bairros, mas pela potência de suas criações" (Leite, 2013, p. 47).

Fica claro que o grafite é a modalidade que está em maior evidência atualmente, já sendo aceito socialmente e também por parte de empresas e escolas. Diferentemente, a pichação e os pichadores são marginalizados e sua atuação criminalizada. A arte de rua, porém, inclui o grafite, a pichação, o estêncil e inúmeras outras modalidades, que podem ser consideradas mais do que apenas expressões artísticas, representando também um tipo de atitude e atuação insubmissa ao status quo. Os artistas de rua não se submetem ou sucumbem à lógica de que somente a propaganda e o neoliberalismo devem configurar os territórios urbanos. Desta forma, estes atores sociais não se deixam dominar pelas formas culturais dominantes ou contextos previamente determinados socioeconomicamente; ao contrário, os artistas de rua (re)apropriam-se de componentes da subjetividade dominante, reinventando novas formas de cul- tura e produzindo processos de singularização pela capacidade de disseminarem atividades semióticas não dominantes.

A limitação do estudo se dá por ser uma pesquisa localizada em uma Federação. A existência de outros estudos feitos em diferentes cidades e seguindo a mesma linha deste atual pode ajudar a perceber melhor como os artistas de rua singularizam-se por meio de intersubjetividade e atuações urbanas. Não sendo uma forma de semiótica dominante, a arte de rua e a atuação dos seus produtores deve ser mais estudada para favorecer novas formas de reflexão e facilitar mudanças na percepção acadêmica e social sobre o tema.

Estes atores sociais atuam segundo a lógica de que o espaço público é de uso comum, o que ajuda a reforçar discussões sobre o direito à cidade. Por meio deste estudo, tornou-se possível ampliar a percepção social sobre o que seja democratizar as cidades através da arte de rua, colaborando, portanto, na renovação da percepção social para a arte de rua. Segundo Minhoto (2014), existe uma luta pelo direito à cidade que vai além da inclusão social e do acesso aos espaços já existentes.

Para o autor, o importante é a criação de "condições sociais que [...] impeçam que o dinheiro e o poder monopolizem e esgotem a construção e a organização dos sentidos na sociedade (p. 1). A cidade deve ser capaz de gerar novas respostas para questões humanas e o valor da contribuição deste estudo também aponta nesta direção, podendo enriquecer ainda mais esta discussão. A arte de rua não favorece ao sistema capitalista, ao contrário, promove a democratização dos espaços públicos e a inclusão de vozes excluídas da concepção semiótica dominante.

\section{Referências}

Araújo, F. F. (2013). Empresariamento urbano no Rio de Janeiro: Reflexões sobre a prática do modelo de gestão (Dissertação de Mestrado). Universidade Federal do Rio de Janeiro, Rio de Janeiro, RJ, Brasil.

Araujo, J. M. (2005). No mundo da arte clandestina: Pichação e grafite, caos colorido que já faz parte da paisagem urbana. São Paulo, SP: Sesc.

Arendt, H. (2004). A condição humana (10a ed., R. Raposo, Trad.) Rio de Janeiro, RJ: Forense Universitária. (Original publicado em 1958).

Assis, B. V. (2012). Arte urbana (arte de rua). Recuperado de http://lounge.obviousmag.org/sobre_linhas_entre_ espacos/2012/04/street-art-arte-de-rua.html\#ixzz3NZcmyS42 
Augé, M. (2005). Não lugares: introdução a uma antropologia da sobremodernidade. Lisboa: 90 Graus. (Originalmente publicado em 1992).

Brasil. (2013). Ministério da Educação. (2013). Manual operacional de educação integral. Retirado de http:// portal.mec.gov.br/index.php?option=com_docman\&view=download\&alias=14458-manual-mais-educacao-2013-final-171013-2-pdf\&category_slug=outubro-2013-pdf\&Itemid=30192

Caldeira, T. P. R. (2012). Inscrição e circulação: Novas visibilidades e configurações do espaço público em São Paulo. Novos Estudos CEBRAP, (94), 31-67. https://doi.org/10.1590/S0101-33002012000300002

Campos, R. (2013). Graffiti writer as superhero. European Journal of Cultural Studies, 16(2), 155-170. https://doi. org/10.1177/1367549412467177

Carvalho, F. J. O. (2013). Risco, rabisco, pichação e grafite: Iconografia de uma estética incompreensível. Rio de Janeiro, RJ: Clube dos Autores.

Ceará, A. T. \& Dalgalarrondo, P. (2008). Jovens pichadores: Perfil psicossocial, identidade e motivação. Psicologia USP, 19(3), 277-293.

Faraco, C.A. (2011). Aspectos do pensamento estético de Bakhtin e seus pares. Letras de Hoje, 46(1), 21-26.

Ferreira Neto, J. L. (2004). Processos de subjetivação e novos arranjos urbanos. Revista do Departamento de Psicologia - UFF, 16(1), 111-120.

Furtado, J. R. (2012). Tribos urbanas: Os processos coletivos de criação no grafite. Psicologia \& Sociedade, 24(1), 217-226. https://doi.org/10.1590/S0102-71822012000100024

Giordano, L. (2014). Leonardo Giordano cobra explicações sobre desrespeito à lei do grafite. Retirado de http://www. leonardogiordano.com.br/noticias/mandato-solicita-explicacoes-sobre-desrespeito-a-lei-do-grafite

Gombrich, E. (2007). Arte e ilusão: Um estudo da psicologia da representação pictórica (4a ed., R. S. Barbosa, Trad.). São Paulo, SP: Martins Fontes. (Original publicado em 1957).

Guattari, F \& Rolnik, S. (1986). Micropolítica: Cartografias do desejo (2a ed.). Petrópolis, RJ: Vozes.

Habermas, J. (1990). Soberania popular como procedimento: Um conceito normativo de espaço público. Novos EstudosCebrap, 26, 100-113.

Heller, A. (1977). Sociología de la vida cotidiana (Trad. J. F. Yvars, \& E. Pérez Nadal).. Barcelona: Península

Lazzarin, L. F. (2007). Grafite e o ensino da arte. Educação e Realidade, 32(1), 59-74.

Leite, A. E. (2013). Grafite em São Paulo: Tendências contemporâneas. Botafogo, RJ: Aeroplano.

Lotman, I. M. (1996). La semiosfera I: Semiótica de la cultura y del texto (D. N. Valência, Trad.). Valência: Frónesis Cátedra.

Marcheri, P. L., \& Rosseto, J. M. (2014). A pichação e a dignidade da pessoa humana. Âmbito Jurídico, 17, 123.

Minhoto, L. D. (2014). Nota crítica sobre a teoria dos sistemas, o neoliberalismo e o direito à cidade. Revista Direito e Práxis, 5(9), 462-474. https://doi.org/10.12957/dep.2014.13741

Molon, S. I. (2003). Subjetividade e constituição do sujeito em Vygotsky. Petrópolis, RJ: Vozes.

Müller, J. (2004). Elementos semióticos no planejamento urbano: O caso de Curitiba. (Dissertação de Mestrado) Universidade Federal do Paraná, Curitiba, PR, Brasil.

Oliveira, G. R. C. (2009). PiXação: Arte e pedagogia como crime (Dissertação de Mestrado). Universidade do Estado do Rio de Janeiro, Rio de Janeiro, RJ, Brasil..

Prosser, E. S. (2006). Intervenção urbana: Vandalismo ou arte? Anais do $1^{\circ}$ Colóquio Nacional do Núcleo de Estudos em Espaço e Representações, Curitiba, PR. Retirado de http://www.neer.com.br/anais/NEER-1/comunicacoes/ elisabeth-prosser.pdf

Rink, A (2013). Grafite: Intervenção urbana e arte. Curitiba, PR: Appris.

Rocha-Coutinho, M. L. (1994). Tecendo por trás dos panos. Rio de Janeiro, RJ: Rocco.

Santos, M. (1996). A natureza do espaço: técnica e tempo: razão e emoção. São Paulo, SP: Hucitec.

Santos, M. (1997). Metamorfoses do espaço habitado. São Paulo, SP: Hucitec. 
Santos, M. (2010a). Por uma outra globalização: Do pensamento único à consciência. Rio de Janeiro, RJ: Record.

Santos, T. M. (2010b). Grafite: A leitura dos muros. In VI Enecult (Encontro de estudos multidisciplinares em cultura) Facom-UFBa, 1-13. Retirado de http://www.cult.ufba.br/wordpress/24406.pdf

Sawaia, B. B. (2008). O ofício da psicologia social à luz da ideia reguladora de sujeito da eficácia da ação à estética da existência. In A. V. Zanella et al. (Org.). Psicologia e práticas sociais (pp. 67-79). Rio de Janeir, RJ: Centro Edelstein de Pesquisas Sociais.

Silva, A. C. (2003). As teorias do signo e as significações linguísticas. Partes, 4(39).

Silva, R. L. (2004). Escutando a adolescência nas grandes cidades através do grafite. Psicologia: Ciência e Profissão, 24(4), 2-11. https://doi.org/10.1590/S1414-98932004000400002

Souza, D. C. A. (2007). Pichação carioca: Etnografia e uma proposta de entendimento (Dissertação de Mestrado). Instituto de Filosofia e Ciências Sociais, Universidade Federal do Rio de Janeiro, Rio de Janeiro , Brasil.

Strapasson, V. M., \& Silva, J. M. C. M. (2011). Um estudo de caso do grafite e de seus processos comunicativos: o "sprayssionismo" na era da informação. VII Jornada de Iniciação Científica, Universidade Presbiteriana Mackenzie.

Tavares, A. (2010). Ficções urbanas: Estratégias para a ocupação das cidades. ARS (São Paulo), 8(16), 21-30. https://doi.org/10.1590/S1678-53202010000200002

Verás, M. P. B.. (2001). Tempo e espaço na metrópole: breves reflexões sobre assincronias urbanas. São Paulo em Perspectiva, 15(1), 3-12. https://doi.org/10.1590/S0102-88392001000100002

Vigotski, L. S. (2004). Teoria e método em psicologia (C. Berliner, Trad.). São Paulo, SP: Martins Fontes. (Original publicado em 1996).

Vigotski, L. S. (2005). Pensamento e linguagem (J. L. Camargo, Trad.). São Paulo, SP: Martins Fontes. (Original publicado em 1987).

Vigotski, L. S. (2011). A formação social da mente (J. Cipola Neto, L. S. M, Barreto, S. C. Afeche, Trad.). São Paulo, SP: Martins Fontes. (Original publicado em 1984).

Will, S. V. (2015). Vigiar, punir, educar e matar: Discursos de disciplinamento, controle e extermínio da população preta e pobre do Rio de Janeiro (Tese de Doutorado). Universidade Federal Fluminense, Niterói , RJ, Brasil.

\section{Anita Rink}

Doutora em Psicologia pela Universidade Salgado de Oliveira. Rio de Janeiro - RJ. Brasil.

E-mail: anitarink9@yahoo.com.br

Ione Vasques-Menezes

Doutora em Psicologia pela Universidade de Brasília (Brasília).

E-mail: vasques.menezes@gmail.com

\section{Marsyl Bulkool Mettrau}

Doutora em Educação pela Universidade do Minho (Portugal) e Pós-Doutora pela Universidade Federal Fluminense. E-mail: marsyl@ig.com.br

Endereço para envio de correspondência:

Alameda São Boaventura, no 890, bloco 5, apto. 502. Fonseca. CEP: 24120-191.

Niterói - RJ. Brasil.

Recebido 30/06/2017

Aprovado 29/11/2017 
Psicologia: Ciência e Profissão Abr/Jun. 2018 v. 38 n², 332-346.

Received 06/30/2017

Approved 11/29/2017

Recibido 30/06/2017

Aceptado 29/11/2017

Como citar: Rink A., Vasques-Menezes I., Mettrau M. B. (2018). Estudo Fotográfico da Arte Urbana: da Aventura Proibida ao Engajamento Político. Psicologia: Ciência e Profissão, 38 (2), 332-346. https://doi.org/10.1590/19823703002512017

How to cite: Rink A., Vasques-Menezes I., Mettrau M. B. (2018). Photographic Study of Urban Art: from Forbidden Adventure to Political Engagement. Psicologia: Ciência e Profissão, 38 (2), 332-346. https://doi.org/10.1590/19823703002512017

Cómo citar: Rink A., Vasques-Menezes I., Mettrau M. B. (2018). Estudio Fotográfico del Arte Urbano: de la Aventura Prohibida al Compromiso Político. Psicologia: Ciência e Profissão, 38 (2), 332-346. https://doi. org/10.1590/1982-3703002512017 